\title{
Unusual location of tuberculosis in the course of tumor necrosis factor $\alpha$ inhibitor therapy
}

\author{
Agnieszka Bielewicz-Zielińska' ${ }^{1}$, Jan Brzezicki ${ }^{1}$, Marcin Rymko², Sławomir Jeka ${ }^{3}$ \\ ${ }^{1}$ Department of Rheumatology, Voivodeship Hospital, Elbląg, Poland \\ ${ }^{2}$ NZOZ Nasz Lekarz, Clinical Trials Office, Toruń, Poland \\ ${ }^{3}$ Clinic of Rheumatology and Connective Tissue Diseases, University Hospital No. 2 Dr. Jan Biziel, Collegium Medicum in Bydgoszcz, \\ Nicolaus Copernicus University in Toruń, Poland
}

\begin{abstract}
Tuberculosis is an infectious disease caused by Mycobacterium tuberculosis complex mycobacteria. Extrapulmonary tuberculosis usually develops more than two years after infection or many years later. Factors favoring onset of the disease are malnutrition, older age, renal failure, diabetes, cancer, immunosuppression and biological treatment, e.g. tumor necrosis factor $\alpha$ (TNF- $\alpha$ ) inhibitors. The paper presents a case of a 56-year-old patient with ankylosing spondylitis treated with infliximab, diagnosed with tuberculosis of the spleen. The unusual location and uncharacteristic symptoms created a lot of diagnostic difficulties, particularly as during qualification for biological treatment tests are performed to exclude infection with Mycobacterium tuberculosis. Pharmacological treatment of tuberculosis is typical, but in the case of tuberculosis of the spleen, splenectomy also is a method of treatment. The decision was made to implement pharmacological treatment, which proved to be effective, so the patient avoided surgery.
\end{abstract}

Key words: tuberculosis, Mycobacterium tuberculosis, anti-TNF.

\section{Introduction}

Extrapulmonary tuberculosis usually develops more than two years after infection or many years later [1]. Treatment with tumor necrosis factor antagonists (antiTNF) increases the risk of developing active tuberculosis (TB) [2]. Prior to administration of a TNF antagonist, active TB should be ruled out and a test should be performed to detect TB infection. About 1/3 of the population is infected with TB (latent form of tuberculosis) [2]. In unhealthy conditions, infected people can become sick [2]. Tuberculosis and opportunistic infections occur more frequently in patients with rheumatoid arthritis (RA), despite non-introduction of the group of disease-modifying antirheumatic drugs (DMARD) or biological therapy. However, in patients with RA treated with TNF- $\alpha$ inhibitors there is about four times greater risk of developing active TB compared to patients not treated with TNF inhibitors [3]. Reactivation of the latent form of tuberculosis can manifest at different times after treatment with TNF- $\alpha$ inhibitors, usually in the first 6 months [2]. Symptoms of TB in patients treated with TNF inhibitors are unusual and in half of cases take extrapulmonary form [2]. Isolated tuberculosis of the spleen is a very rare disease. The diagnosis is often difficult. Similar symptoms can occur for other reasons. On the basis of imaging the disease can be suspected, but the final diagnosis is based on histopathological findings $[4,5]$.

\section{Case report}

The 56-year-old patient, with a diagnosis of ankylosing spondylitis (AS) from 1994, was previously treated with non-steroidal anti-inflammatory drugs (NSAID),

Address for correspondence:

Agnieszka Bielewicz-Zielińska, Department of Rheumatology, Voivodeship Hospital, 1 Maja 58/13, 82-300 Elbląg, Poland,

e-mail: agabielewicz@poczta.onet.pl

Submitted: 2.04.2015, Accepted: 26.06.2015 
methotrexate (MTX), sulfasalazine, and methylpred nisolone. On 14.04.2011 he was admitted to the Department of Rheumatology, due to high fever to $40^{\circ} \mathrm{C}$. Confluent night sweats, weakness, without coughing and lumbar pain as exacerbation of ankylosing spondylitis were observed. He reported a history of thrombocytopenia and cavernous transformation of the portal vein [in the abdominal ultrasound (US) examination portal vein in the liver hilus region with a diameter of $1.7 \mathrm{~cm}$, tortuous with a number of internal reflections]. Due to the active form of AS with BASDAI (Bath Ankylosing Spondylitis Disease Activity Index) 8.7, the patient was qualified for biological treatment. In the qualification testing the interferon- $\gamma$ release assay as the Quantiferob TB - Gold test, which was negative, and up-to-date chest- $X$ ray (not older than 3 months before receiving the TNF- $\alpha$ inhibitor) were done. The patient received two infusions of infliximab with good tolerability and a significant improvement. During the hospitalization in laboratory tests: ESR - $47 \mathrm{~mm} / \mathrm{h}, \mathrm{CRP}-62 \mathrm{mg} / \mathrm{dl}, \mathrm{Na}-128$ $\mathrm{mmol} / \mathrm{l}$, serum glucose $-129 \mathrm{mg} / \mathrm{dl}$, D-dimer $-608 \mathrm{ng} / \mathrm{ml}$; blood count and urinalysis were normal, blood and urine cultures negative, LDH, CK, procalcitonin, proteinogram, exponent of coagulation (INR, PT), amylase, aminotransferase (AST, ALT), urea, creatinine were normal. Chest X-ray image was normal, abdominal ultrasonography (US) revealed abnormalities as enlarged liver and spleen of normal echogenicity, tortuous portal vein with numerous internal reflections. Due to US imaging the abdominal computed tomography (CT) was performed and showed enlargement of the liver, hypodense liver foci size 2-10 mm and suspicion of small cysts, tortuous portal vein of $20 \mathrm{~mm}$ diameter, enlarged spleen with many small hypodense foci mainly visible on CT scan after contrast. No enlarged lymph nodes were visualized. Than abdominal MRI was performed, and revealed moderately enlarged spleen, and in the dynamic examination after intravenous contrast administration heterogeneous strengthening of the spleen intensity drew attention, with separate very small 2-5 mm areas with lower signal. Some of them showed trace diffusion-weighted imaging (DWI) diffusion restriction. The patient received antibiotics (i.v. BID ciprofloxacin $0.4 \mathrm{~g}$ and $1.0 \mathrm{~g}$ cefuroxim BID i.v.), ketoconazole and 4 infusions of methylprednisolone $125 \mathrm{mg}$. During therapy it was observed that the patient was still febrile and that was the reason for further evaluation. The Quantiferon - TB Gold test was performed once again with a positive result. The patient with the suspicion of TB was referred to the Pulmonology Department. Bronchofibroscopy was performed and in the bronchial lumen a significant amount of foamy secretion was revealed, which was taken for direct bacterioscopy (BS), polymerase chain reaction (PCR) and cytology testing. Cytological examination did not reveal tumor cells or components of specific inflammatory granulation. In a BS of bronchial aspirate and sputum, acid-resistant mycobacteria were cultured. In the mycobacteria growth indicator tube (MGIT) system, a bronchial lavage culture of Mycobacterium tuberculosis complex was cultured. Acid-Fast Bacilli (AFB) smear of bronchial lavage using the Ziehl-Neelsen method was negative. In the ProbeTec ET system, a test sample of bronchoalveolar lavage was positive (test to perform qualitative and direct DNA of Mycobacterium tuberculosis evaluation from disinfected samples from respiratory system). The blood culture was negative.

The patient was treated from 9.05.2011 with the antimycobacterial drugs rifampicin (RMP) 0.6, isoniazid (INH) 0.3, pyrazinamide (PZA) 1.5 and ethambutol (EMB) 1.0 without complications and with clinical and radiological improvement. The patient was discharged on 07.07.2011 with a final diagnosis of tuberculosis of the lungs and spleen.

\section{Discussion}

Tuberculosis is an infectious disease, caused by acid-fast bacilli belonging to the Mycobacterium tuberculosis complex [6]. It can affect the lungs and other organs (extrapulmonary tuberculosis). Extrapulmonary tuberculosis is not common and is responsible for only about $15 \%$ of cases of tuberculosis [7]. There is tuberculosis of the abdominal organs, which accounts for $11 \%$ of extrapulmonary cases [8]. The spleen is the third most common organ (75\%) of miliary tuberculosis. In the first place are the lungs (100\%) then the liver (82\%) [8]. There are two clinical types of spleen tuberculosis. More frequent is diffuse or miliary occurring in a patient with immunodeficiency [7]. The reported patient may be included in a group of persons with reduced immunity due to an autoimmune disease and TNF- $\alpha$ inhibitor treatment.

Disorders of the immune system are an important risk factor for spleen tuberculosis, including blood disorders, diabetes, acquired immunodeficiency (AIDS), rheumatic diseases, organ transplantation and chronic glucocorticoid therapy [9]. The second type is primary spleen tuberculosis, which is extremely rare [10].

The common symptoms are usually non-specific, mainly fever and increased ESR and CRP level, as in the described case [11]. In addition, the patient reported sweating, especially at night. Sometimes there is pain in the left upper quadrant of the abdomen and weight loss [12]. Those symptoms did not occur in the presented case. There was also lymphadenopathy. Fever of un- 
known origin also allows differentiation from lymphoma, when pain in the spleen may also occur [9].

There were no changes in chest radiography in the described patient. In the abdominal ultrasonography enlargement of the spleen, without the presence of focal lesions, was observed. Ultrasonography examination is a simple, non-invasive, and often used examination, but having limitations [11]. Ultrasonography can be helpful in the diagnosis of spleen tuberculosis as well as in the assessment of response to therapy [13]. Micronodular tuberculosis is a more frequent form and mostly concerns disseminated tuberculosis. If the changes are too small to be detected by imaging, it manifests as a simple enlargement of the spleen, as in the present case. Macronodular tuberculosis of the spleen is rare and can manifest in a single large nodule [7]. Typically, during diagnosis it is necessary to perform abdominal CT. The patient was found to have numerous small hypodense foci mainly visible after contrast. Computed tomography is very helpful especially in differentiating abscess of the spleen, but also has limitations. Numerous hypodense foci may also be present in lymphomas, meta, echinococcal cysts, hemangiomas and even in infectious diseases and fungal infections. Fungal infection of the spleen is diagnosed more often especially in people with weakened immune systems. Most frequently yeast such as Candida albicans are found [7].

In the case described, MRI of the abdomen was also performed, where 2-5 $\mathrm{mm}$ hypodense areas and a trace of DWI diffusion restrictions were revealed. Similar changes occur in sarcoidosis and lymphoma. However, there was no adenopathy or changes typical for sarcoidosis in chest $\mathrm{X}$-ray in this patient. Absence of strong restriction features allowed us to exclude abscess, fungus and hemorrhagic tumor [7]. Meta character of changes seemed unlikely, due to the lack of clinical data on cancer. Lack of strong restriction features within the foci spoke against abscesses, but this effect may be due to the very small size of foci. The gold standard for confirming the diagnosis is microbiological and histopathological examinations of material obtained from splenectomy or biopsy [9]. Many patients do not accept invasive methods. Laparoscopic surgery is less invasive and can obviate the necessity of splenectomy [11]. Histopathological examination shows typical granulomas with epithelial cells and giant Langerhans cells [8]. In some cases, splenectomy is not only a diagnostic method, but also an effective treatment [14]. However, it is recognized that treatment with anti-tuberculous drugs is the first line treatment. Surgery may be performed if pharmacological therapy fails [9]. According to other reports, treatment should be a combination of those methods and should last more than 6 months, and pharmacotherapy should be used before and after the operation, if it has been made [11]. According to some studies, drug therapy should be used for 12 months, although an inadequate response to such treatment is observed without splenectomy [8].

\section{Summary}

To summarize, in the described patient the diagnosis of tuberculosis was confirmed on the basis of microbiological examinations and the radiological image despite the uncharacteristic clinical picture and laboratory tests. The used pharmacological treatment, without splenectomy, proved to be effective. This was confirmed by resolution of symptoms and radiographic changes.

The conclusion from the above work is that in diagnosing a patient with rheumatic disorders with fever and other general symptoms that may exist in AS and other inflammatory diseases, one should always take into account tuberculosis despite IGRA tests. Even if lung tuberculosis is not confirmed, there is a risk of extra-pulmonary tuberculosis, especially in patients with other risk factors of immunodeficiency.

The authors declare no conflict of interest.

\section{References}

1. Kołaczewska M. Czy w Polsce istnieje problem gruźlicy pozapłucnej? Przew Lek 2007; 4: 101-106.

2. Korzeniowska-Koseła M. Zapobieganie gruźlicy u chorych leczonych antagonistami czynnika martwicy nowotworów. Reumatologia 2010; 48: 4-13.

3. Wisłowska M. Praktyczne aspekty leczenia chorób reumatycznych. Zakażenie $u$ chorych na reumatoidalne zapalenie stawów leczonych biologicznie.

4. Dalal S, Nityasha, Dahiya RS, et al. Isolated tuberculosis of spleen: a rare clinical entity. The Internet Journal of Surgery 2008; 16 (1). Available at: https://ispub.com/IJS/16/1/9879.

5. Joshi S, Bankar M, Kagal A, et al. Splenic tuberculosis - a rare case report. Internet Journal of Medical Update 2007; 2: 3841.

6. Grzelewska-Rzymowska I, Korzeniewska-Koseła M, Kruczak K. Gruźlica i mykobakteriozy. W: Interna Szczeklika 2014. Medycyna Praktyczna, Kraków 2014; 725-737.

7. Lim J, Yu JS, Won Hong S, et al. A case of mass-forming splenic tuberculosis: MRI findings with emphasis of diffusion-weighted imaging characteristics. J Korean Sci 2011; 26: 457-460.

8. Ray S, Kundu S, Goswami M, et al. Isolated tubercular splenic abscess: can we defer splenectomy? Our single experience with anti-tuberculous therapy alone. Indian J Med Microbiol 2012; 30: 101-103.

9. Gupta P, Fotedar S, Agarwal D, et al. Tuberculosis of spleen presenting with pyrexia of unknown origin in a non-immunocompromised woman. Lung India 2008; 25: 22-24. 
10. Mahmud TAK, Chowdhury MAJ, Rahman MS, et al. Splenic tuberculosis: A case report. Bangladesh J Medicine 2008, 19: 3132.

11. Zhan F, Wang HJ, Lin JZ, et al. Isolated splenic tuberculosis. World J Gastro Pathol 2010; 15: 109-111.

12. Lonkar Y, Parikh S, Kumar S, et al. Splenic tuberculosis presenting as ascites in immunocompetant patient. Ann Med Health Sci Res 2013; 3: 116-118.

13. Sharma SK, Smith-Rohrberg D, Thair M, et al. Radiological manifestation of splenic tuberculosis: a 23-patient case series from India. Indian J Med Res 2007; 125: 669-678.

14. Rodarte-Shade M, Diaz-Elizondo JA. Splenic tuberculosis. Surg Infect (Larchmt) 2012; 13: 420-421. 